\title{
Correction to: Selective determination of mandelic acid in urine using molecularly imprinted polymer in microextraction by packed sorbent
}

\author{
Esmaeel Soleimani ${ }^{1}\left[\right.$ [ $\cdot$ Abdulrahman Bahrami $^{1} \mathbb{D} \cdot$ Abbas Afkhami $^{2} \cdot$ Farshid Ghorbani Shahna $^{1}$
}

Published online: 8 January 2018

(c) Springer-Verlag GmbH Germany, part of Springer Nature 2018

\section{Correction to: Arch Toxicol}

\section{https://doi.org/10.1007/s00204-017-2057-z}

In the original publication of the article, there is an error in Fig. 2c. The authors would like to correct this error and the corrected version of Fig. $2 \mathrm{c}$ is as follow:

The original article can be found online at https://doi.org/10.1007/ s00204-017-2057-z.

Abdulrahman Bahrami

bahrami@umsha.ac.ir

Esmaeel Soleimani

e.soleimani@umsha.ac.ir

Abbas Afkhami

afkhami@basu.ac.ir

Farshid Ghorbani Shahna

fghorbani@umsha.ac.ir

1 Department of Occupational Health, School of Public Health, Hamadan University of Medical Sciences, PO Box 65175-4171, Hamadan 6517838695, Iran

2 Department of Analytical Chemistry, Bu-Ali Sina University, Hamadan, Iran

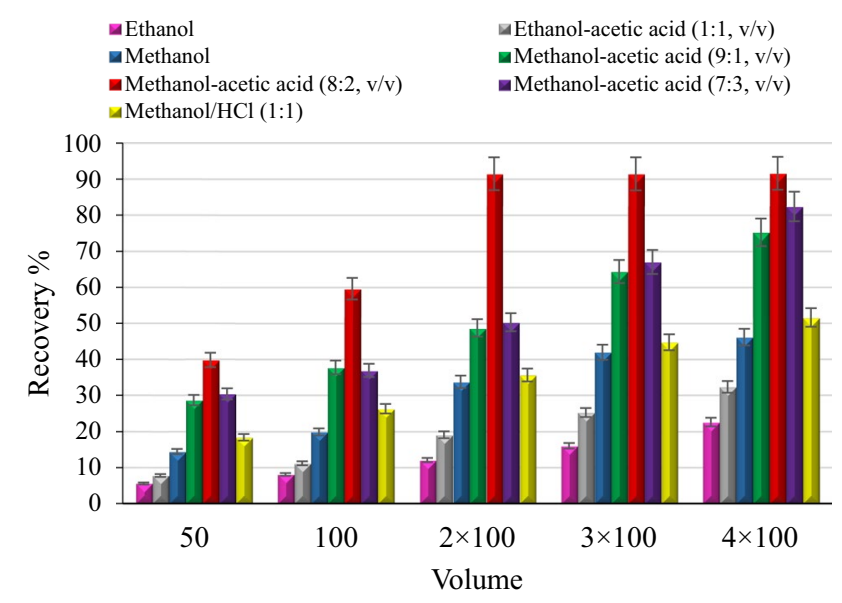

